\title{
META-SYSTEM APPROACH AS A METHODOLOGICAL PRINCIPLE OF PSYCHOLOGICAL RESEARCH
}

\author{
Anatoly V. Karpov \\ Demidov Yaroslavl State University \\ Yaroslavl
}

\begin{abstract}
The following article aims to explain why including a new principle - a meta-system approach principle - in methodological principles of psychological research is of crucial importance. In developing main points of system methodology this approach simultaneously appears to be a more general one, because it permits to overcome a number of limitations and, first of all, to incorporate a qualitatively unique class of systems - systems with an "embedded" meta-system level - in the sphere of research. Besides, the article covers main issues and methodological sources for applying the meta-system approach to psychological studies. It is the purpose of this article to demonstrate efficiency of the approach in understanding basic structural principles and content of the highest psychical level - the metasystem level.
\end{abstract}

Keywords: meta-system approach, methodological principle, systems theory, level of organization, subjective reality, structural-level organization, mental representation.

It is well known that the system approach as a methodological principle of psychological research has ended up in the centre of diverse and controversial discussions. Moreover, general feelings about this approach tend to assume a more negative shade which reflects certain skepticism regarding its heuristic power. In this connection the task of conducting a special analysis of the current situation and determining possible way-outs is rather important in the methodological sense. In view of the aforesaid, in this article we will attempt to solve this task which, in its turn, requires an answer to the following main question: Does the current situation mirror objective logic of development of psychological cognition or is it rather a "methodological aberration" and an indicator 
Meta-system Approach as a Methodological Principle of Psychological Research 155

of any other transitional phenomena in its development? What are the prospects and outlines of the system approach?

It goes without saying that the current situation is determined by multiple factors, it is originated by a number of reasons; some of them have been well-known, they are in a way lie "on the surface"; other reasons are of a more implicit nature and need analyzing. Thus, the following main reasons relate to the former group:

1. Substitution of adequate understanding of the system approach as a methodological approach as such with its inadequate interpretation as a research method. As a result, the system approach is viewed as a sufficient means (in fact, quasi-sufficient) for planning and carrying out specific research projects. Basically, it does not lead to any positive results thereby creating incentives for a negative attitude towards the approach.

2. Insufficient methodological "culture" of research projects, in which attempts to apply the system principle were made. Consequently, these research attempts appeared to be somewhat superficial, while the system approach exhibiting (more precisely, quasi-exhibiting) in them compromised itself.

3. Incomplete and therefore inadequate, only partial implementation of the system approach. It was not seldom that only an individual aspect of the system approach was realized in researches (yet often in a rather correct manner). However, the whole inventory of methodological instruments and true potential of the approach in question has not been implemented.

4. Absolutely incorrect application of the system approach to such problems that do not require it at all, since they may be solved more efficiently by other methodological and methodical instruments. It constitutes a breach of one of the basic methodological requirements, according to which any theory and any approach should have their own degree of generalization and a field of application. This gave rise to some studies that L.S. Vygotsky characterized as sewing up a "methodological coat" to an "experimental button"; a phenomenon of "system reductionism" has become widespread.

It should be emphasized that all the aforementioned reasons are rather associated with imperfections deriving from application of the system approach, not with deficiencies of the approach itself. However, it would be an unacceptable simplification to reduce the present-day state of system studies exclusively to the latter. In our opinion, there is an- 
other group of factors having a more implicit and, simultaneously, more fundamental character. They are not connected with some "deficient application," but with the insufficient level of development of the system approach itself. The system approach in its contemporary form is not something "completely shaped" and "finally developed"; on the contrary, from our standpoint, it would be more productive to treat the system approach as a developing principle. By virtue of the stated above, numerous disadvantages that emerged during the application of the approach have to be interpreted not as created by its attributive limitations, but as derived from the insufficient level of its development.

In connection with the conclusion drawn above it is necessary to define an issue that appears to be fundamental and of critical importance for the methodological reflexive review of the system principle, as well as for determination of prospects concerning its further development. Can the system approach as such (not only means of its application) be advanced and improved in comparison with its present state? If the answer is "yes," then how exactly? Does the approach itself contain certain implicit prerequisites and conditions for its further development? At the same time, it is highly likely that its further improvement won't be superficial in nature, but rather will require its significant transformation.

There is no doubt that all these questions are extremely complicated and require a large complex of specific methodological research. We should point to a very meaningful fact that such research is driven directly by most serious contemporary attempts to develop the system approach. For instance, elaboration of the system approach includes introduction of a concept of "poly-system" (Zavalishina, 1995, pp. 32-42); substantiation of an "intersystem" approach (Golikov \& Kostin, 1996); intergraded methodological development of basics of the system approach in papers by V.A. Barabanschikov (Barabanschikov \& Nosulenko, 2004); efforts to integrate fundamental points of the system approach with main foundations of synergetics (Krylov, 1998; Haken, 1980; Prigogine \& Stengers, 1986); elaboration of new versions of the system approach in terms of memetics, a recently emerged academic discipline (Yzerbyt, Lories, \& Dardenne, 1998).

What we are going to do further in this paper is to try to consider some these issues with a particular account of the fact that the presentday concepts in this sphere can allow for a preliminary and speculative answer only. 
Meta-system Approach as a Methodological Principle of Psychological Research 157

II

We have every reason to assume that further advancement of the system approach is possible only provided that specific aspects of structures of systems, which are the most crucial and fundamental category, are subjected to a more complete, precise and adequate consideration. In this regard it is necessary to pay particular attention to a meta-system level (and, consequently, to reality defined by this concept) which appears to be a very important "system concept."

Even early research into the general theory of systems (Bertalanffy, 1974) has differentiated this level from other levels and has shown that the meta-system level is not just a hierarchically highest, but an "open" one, too. In particular, it implies that by means of this level a system communicates with other systems and evolves within such communication. We have to admit, though, that the concept of a meta-system level has been a kind of "unfortunate" one, if we consider attention concentrated on it and, consequently, the extent to which this concept has been examined. Obviously, it has been largely caused by complexity, inconsistency and, in a way, paradoxicality of the level itself. Besides, such inconsistency and ambiguity is embodied in the etymology of the "meta-system" concept itself: it indicates that some entity (a level in our case) both belongs to the system and simultaneously falls beyond the latter. Then the following question arises: where is the level under consideration located "in fact"? The second of the two mentioned arguments is traditionally accepted, yet sometimes in a simplified form, when the meta-system concept reflects only the involvement of a system in other systems of higher hierarchy (i.e. meta-systems) and interaction between them. It would be appropriate to repeat here that this simplified interpretation, in our opinion, fails to cover all complex and specific traits of the meta-system level and to explain the concept. This interpretation merely reflects a trivial fact of the interaction between a system and a meta-system instead.

In addition to the above-stated, research on another specific phenomenon which is identified as a "paradox of the higher system level" can enhance advancement of conceptualization within the system methodology. The core of this phenomenon is as follows. On the one hand, being located within the system yet not covering the system in its entirety (by definition) the top level in the hierarchy of any system turns out to be a part of this system. This part may be crucial, decisive, predominant, etc., and still it remains a part of the system. It performs coordinating, 
organization and control functions in regard to other parts of the system. On the other hand, any system (especially, a complicated one) may be organized efficiently, only if an object of its "coordinating and control" center is not just a part of the system, but the whole system, its entire content. Therefore, it gives rise to an internally controversial situation when the higher level of the system has to be included into the system and simultaneously stay "outside" and "beyond" its content, to be more specific, "above" it. As a matter of fact, this difficulty has been occurring for a long time, and efforts to overcome it lead to, for instance, identifying a "control supersystem" (which requires a "supreme" supervision itself, though) within a system, and all these generates a typical situation of "bad infinity". The same difficulty appears to be the main ground for the "homunculus idea" in psychology. In our view, the most natural, though rather radical, way of overcoming the discussed paradox can be an assumption that a level which simultaneously can be a level of the system and a level beyond it (a meta-level), it means be placed outside the system, may exist in the very content of systems (including psyche as a system). ${ }^{1}$

Consequently, we can suggest that disclosing the nature of the metasystem level may advance further development of the system principle. At the same time, this advancement still remains controversial, unclear and in a way even paradoxical. First of all, this paradoxicality is associated with the fact that the meta-system level viewed as belonging to a system and even interpreted as system's "highest and leading" level (by definition) is not included in the structure and content of this system, as a rule, but rather is located outside the system in the light of its interactions with more general entities - meta-systems. Traditionally accepted and shared beliefs in this domain that have become axiomatic and "canonic" prefer to "ignore" this controversy and paradox of the meta-system level concept (in order to preserve conceptual comfort). Nevertheless, as it follows from the foregoing, these beliefs can be and should be significantly specified and, partially, corrected. Further development of the system approach itself is questionable without such a correction.

$1 \quad$ At first this assumption may appear groundless and even unrealistic. However, we do not suggest jumping to evaluations and conclusions, because one should bear in mind, for instance, the role that views on "anticipating reflection" mechanism, once even less evident, played in psychology (Anokhin, 1978). 
Meta-system Approach as a Methodological Principle of Psychological Research 159

The nature of such "canonic" viewpoints can be summed up as following. When an object is studied in terms of the system principle, a series of hierarchically related levels are outlined within a system. Besides, any system is described by two classes of interactions - inter- and intra-system interactions. The former provide involvement of a system within the context of more generalized (in regard to the system itself) systems that are referred to as meta-systems. These interactions comprise the content, a kind of "texture" of the meta-system level. Thus, both the content and therefore the meta-system level itself - by definition are exposed in a so called "extra-system" dimension. In other words, the aforementioned viewpoints basically underline the existence of system's interactions with more generalized meta-systems along with a crucial role of these interactions for functioning of the system itself. Hence, a question of consistency and versatility, it means "universality" of the beliefs, their sufficiency for description of the variety of existing systems in general, and psyche, in particular, becomes urgent.

\section{III}

From our point of view, in order to try to answer the question posed above, it is advisable to sharpen this question deliberately and word it as follows: is the statement that the meta-system level can be located only outside a system universally applicable to all types of systems existing in reality? Or is such "extra-system" location just a particular, even though most typical and widespread, but not general, structural pattern of systems?

In our attempt to answer this question, we find necessary to underline the following. The whole background of psychology, its most general basics, as well as attributive essence of psyche, point to existence of basic and fundamental, and allegedly the most universal principle of its organization. Moreover, this principle appears to be so general and its aspects and manifestations are so diverse, while the principle itself seems "conventional and habitual," that there is no need disclosing it in detail. Instead, it would be sufficient to consider its meaning: external objective reality (as a meta-system with which psyche originally interacts) acquires a certain kind of twofold existence as subjective reality, in the form of what is called "the reflected" (if we turn to the traditional terminology). 
The subjective reality may take various shapes, it may be designated and construed in a different manner in view of its mechanisms, structures and processes, but the very fact of its existence is unquestionable and unalterable. ${ }^{2}$

Psychology offers a variety of concepts employed to identify this reality and its variations, forms, aspects, explications, etc. Here are just some of them: "internal information," "knowledge," "mental representation," "cognitive schemas," "experience," "image of the world," "internal world," "model of a situation," "subjective representations," "scripts" and many others.

In other words, the attributive nature of psyche and at the same time its unique character (which was formerly referred to as its "reflective nature") is such that objective reality acquires its "dual existence" in it in the form of subjective reality. Further, the more completely and adequately the latter corresponds with objective reality, the more opportunities are provided for fulfilling the tasks of general adaptation. We may thus state that the meta-system with which psyche originally interacts, in which it is objectively included and which is given to psyche externally, appears to be presented in a certain way in the structure and contents of the psyche itself. This meta-system is transposed into psyche, even though in a rather specific form, namely, as subjective reality (which according to its essence and purpose must be of maximum similarity to objective reality in terms of its informational and content characteristics). Of course, the most complex and important gnoseological question deals with the issue of how exactly it happens? How is subjective reality created while interacting with external, objective reality? In fact, this question represents the main issue of psychology, and it is not ready to give a satisfying answer to it so far. However, the very fact of creation and, accordingly, existence of subjective reality as "doubled" objective reality is accepted and beyond any doubt. Although, it "eliminates doubts" so explicitly that this fundamental fact if often taken for granted, but is not taken into consideration in dealing with some research tasks. To be more precise, it attracts insufficient attention in studies based on the system approach principle, as well as while elaborating the content of the system approach, which is more frustrating.

2 Besides, it is clear that the degree if its obviousness is even greater if compared to obviousness of existence of objective reality itself, which laid the foundation to a number of philosophical approaches and doctrines. 
Meta-system Approach as a Methodological Principle of Psychological Research 161

Thus, the nature of psyche is such that the meta-system which is "externally given" with respect to it and in which it is objectively included is represented in its own content. It should be emphasized that we refer to a certain form of existence of this objective reality as opposed to its ontological representation in psyche. Besides, the more complete, adequate and so-called "global" is such representation of the meta-system in the content of psyche, the more psyche "wins," because its adaptive and other capabilities tend to increase.

A direct logical conclusion from the described above is that interaction of psyche (as a system) and meta-systems, in which it is originally included, may be performed without any actual contact with these metasystems. Reality that is difficult to question is such that any interaction with the external world is considerably mediated by its "internal representations" of the world. An individual interacts not as much with the "world" directly, but with his / her representations of it, its subjective model. Although this fact is not commonly realized and represented subjectively. As A.N. Leontiev remarked, "It is the world that lies in front of a person, not the 'world' and the 'worldview"' (Leontiev, 1983). It is evident that systems capable of interacting with the environment without any actual contact with it get great advantages. In particular, one gets prepared to possible variants of real interactions, orientation in general situations of possible interactions, receipt of advantage in time for processing large data arrays, etc. The well-known phenomena of a "reflexive pause," as well as an "anticipating reflection" mentioned before are among many demonstrative and clear examples of the foregoing.

\section{IV}

All the questions discussed above are of a general nature and are based on fundamental, starting and broad psychological views. At the same time, all of them are now assimilated by the system methodology to a very slight extent. The fact that the system approach, i.e. the system methodology targeted at solving the most general issues, still does not pay proper attention to these (let's repeat it) fundamental questions, seems paradoxical and even astonishing. Vice versa, attempts to synthesize these questions with the system approach methodology allow to arrive at a number of conclusions which are significant in our view. Here it should be explicitly stressed that such synthesis is not meant as for- 
mal, or "mechanical," and external. On the contrary, it is determined by the internal logic of system approach development, as well as by main trends in advancement of general psychological ideas about structural and functional organization of psyche. It is proved by the very first and simultaneously the most crucial and broad conclusion which can be drawn on the basis of such synthesis. According to this conclusion, it should be acknowledged that the structural-functional organization of psyche implies involvement of the meta-system level precisely in its core, its own structure.

Concerning psyche the meta-system level provides not only the "extra-system" representation (as is true in relation to nearly all other currently known systems), but the "intra-system" representation as well. A meta-system that in regard to psyche includes the entire objective reality externally given to it (as well as interactions with such reality) receives its "doubled existence," "twofold being" in the content of psyche itself. It definitely is not equal to ontological presence, and takes other forms in the qualitative sense. The crucial distinction of all the aforementioned forms from the "original being" of a meta-system is expressed by the controversial character they have relative to this "original being": they are of an ideal instead of a material nature. As we have noted, psychology has worked out a variety of terms to designate them. And vice versa, the meta-system level comprises and synthesizes these crucial psychical formations, while the concept of a meta-system level appears to be generic concerning each of them being specific.

It is necessary to bear in mind that intensification of such research into these forms of subjective representation of objective reality is rightfully one of the main tendencies in general psychological research nowadays, which is explicitly represented in contemporary cognitive psychology and meta-cognitivism. This research is directed to disclosing mechanisms and principles of a structural and functional organization of "mental representations," "knowledge systems" etc. However, it is important to understand not only these mechanisms and principles, but to explain the purport, psychological status of the formations mentioned above in the general structure of the psychical. Their status is defined by belonging to a special meta-system level which, according to its content, represents the "otherbeing" of objective reality in the form of subjective reality, in the form of its ideal models and representations. This gives rise to an important consequence. Knowledge, "subjective information," 
Meta-system Approach as a Methodological Principle of Psychological Research 163

"mental representations" and, in a broader sense, all substantial and information-containing formations of psyche, being the reflection of objective reality, are not purely information formations; rather they possess the status of a structural level in general organization of psyche. This level interacts with all other hierarchical levels of it. Thus, the system of knowledge (again in a broad sense, i.e. including all information content of psyche) becomes subordinate to general structural-level principles. If we slightly simplify the discussed conclusion, we may say that knowledge becomes capable of controlling the structure; the content gets the status of a functional dynamics determinant.

Some other theoretical problems, specifically, the one identified above as the "paradox of the leading system level" may be overcome from the position of these stated assumptions. One can easily see that abovesuggested interpretation of the meta-system level as a positively dual and incorporating two main forms of existence permits a quite natural and even requisite solution for the paradox in question. Actually, with respect to the structure of psyche, this level is "embedded" in its own structure and, moreover, acquires a leading, highest status in it. This level thereby finds its intra-system being and exists exactly as a level within the general structural-level organization of psyche. We have already pointed out before that, having this status, it is manifested in the form of various formations that have been studied in detail by psychology, especially by cognitive psychology and meta-cognitivism, for a long time. However, considering its information and content characteristics, its "substance content," this level appears to be a "duplicate" of objective reality, a product and a result of its "reflection," to be more precise, its recreation, origination. It should be emphasized once again that the more precise and complete appears to be the correspondence of these information and content characteristics to objective reality, the more efficiently functions both the level itself, other levels hierarchically related to it, and psyche on the whole. Being located naturally in the "intra-psychic" dimension, a subject localizes this level outside its boundaries - in objective reality. ${ }^{3}$

3 It is well known that one of the applications of this general characteristic is the "ontological paradox of psyche," identified by L.M. Vekker on the grounds of his research into perception processes: components that are in reality (ontologically) represented in psyche's content (for instance, a perceptive image) are subjectively moved beyond its limits and are localized where the object is located (Vekker, 1974). 
For this reason the level under consideration is subjectively "carried out" beyond the limits of psyche, simultaneously staying inside it, of course.

Therefore, both the "paradox of the highest level of organization" and the problem of uncertainty of the conceptual status of the term "meta-system level" can be solved, as we view it, only if a general scientific principle of complementation is employed. As it has been demonstrated above, the essence, specific traits and attributive nature of the meta-system level are such that it cannot be understood according to the "either or" principle (i.e. as located either inside psyche or outside the same).

A reasonable and correct explanation may be provided by the "both and" principle, stating that the meta-system level has the "dual localization." Besides, this "dual localization" of the meta-system level implies existence of its two main forms or modes - material and ideal.

We believe that the ideas presented above are to be taken into consideration in psychological studies based on the system approach principle. The ideas pose a number of questions and enable to define the most general of them. What will the consequences be, if the meta-system level is included into the structural-level organization of psyche precisely as its own level, not only as a level localized outside it, within its interactions with meta-systems in which psyche, in its turn, is objectively included? In our opinion, the most significant conclusion here is that due to such "inclusion" of the meta-system level in the system itself, preconditions for occurrence of qualitatively new and original mechanisms, principles of structural organization and functioning of psyche are created. Thus, this level (as the level that is both included in the system's content and is "moved" beyond its limits) offers a system an essential possibility for self-objectivation as a subject of organization and control. The system is found to be able to overcome its own boundaries and become a subject of its own influences and activities, without violation of its consistency and "ontological completeness." The most evident and unquestionable phenomenological "indicator" of the characteristic discussed appears to be the complex of so-called "reflexive phenomena." In other words, emergence of the "built-in" meta-system level does not solely imply that "one more" level of utmost importance, even if it is the highest level, appears in the structure of the whole (psyche). The other reason is this level is attributively connected to the new principle of functional organization of psyche (and is even based on it). This principle reflects that the meta-system level (as to the level simultaneously localized both inside 
Meta-system Approach as a Methodological Principle of Psychological Research 165

and outside the system) that provides the system with an opportunity to make itself (by stepping out to this level external in relation to the system) on the whole as an object of its own influence, supervision and organization. ${ }^{4}$

The foregoing may be designated as a meta-system principle of functional organization of psyche. It is to remind here that it is closely connected with the inclusion of the meta-system level in the structure of psyche and, moreover, serves as a foundation therefore. One has also bear in mind that the status of the "principle" notion as such implies a rather broad character of its application and multiplicity of spheres where it can exist. Consequently, there are reasons to suppose that this principle describes not only the interactions between the meta-system level and other hierarchical levels of the system in its entirety, but penetrates many other levels, which are important yet more particular aspects of its organization as well.

The same assumption may be worded in another manner. Having arrived at the meta-system principle of organization as a general one during its evolution, psyche as a highly organized system is capable of replicating it in its specific applications either. This conclusion, which is considerably important, in our opinion, has been confirmed by various psychological data and results including the results obtained by the authors; now let's touch upon just one result of this kind.

In a series of our research projects we have offered a concept of structural-level organization of the system of psychical processes comprising five basic levels of its organization (Karpov, 2003; 2004a). In fact, this concept allows to include in the system such process formations that can't be reduced to traditionally identified classes of psychical processes (i.e. to so-called "primary processes") as, first of all, reflection, integral psychical processes, "meta-processes" etc. This enables to overcome one the main difficulties, according to which traditionally accepted assumptions in studying psychical processes prevent assimilation of these extremely complex process formations into the system common to them. These processes having complex content and synthetic by structure do not "fit in" the traditional systematics and shared structural-level ideas, and frequently even fail to be accepted. Although, the above-discussed

4 In this connection one can see that the approach proposed in our research sets the traditional problem of self-organization from a novel point of view and suggests its solution to some extent. 
ideas characterizing specific traits of the meta-system level and its role in organization of psyche permit to obviate these difficulties to a certain degree.

As a matter of fact, the meta-system level and its "inclusion" in the system itself (psyche) guarantee existence of a fundamental phenomenon (to be exact, a mechanism) which can be defined as a mechanism of meta-system convertibility. Its essence is as simple and understandable phenomenologically as is difficult for a specific scientific explanation and includes the following. This level makes the system with the "embedded" meta-system level objectify itself for the purpose of its own activity (regulation, organization, coordination, etc.). Within the system (psyche) as such a special "functional organ" and special mechanisms are formed that allow a part of the system (i.e. the meta-system level) in a way to oppose itself regarding the system as a whole, to perceive itself as a "wholeness." As a result, being transposed to the meta-system level, any process occurring in psyche becomes directed not to the "environment," but to the internal content of psyche (and often even to itself). This leads to a well-known phenomena and processes that are referred to as "thinking about thinking" (meta-thinking), "memory of memory" (meta-memory), "secondary attention," "meta-cognitive monitoring," i.e. meta-cognitive processes (Flavell, 1979; Metcalfe \& Shimamura, 1996; Nelson \& Narens, 1990), and more traditionally as reflexive processes and phenomena. In other words, those processes and mechanisms that are a part of the psyche originally and are realized on all the levels except the meta-system level may be transferred to the meta-system level as well. In this event the processes a sort of oppose themselves and objectify themselves in relation to the system; they become oriented to the entire system of psyche, as well as to its separate components. As a result, all the in-system processes, mechanisms, principles, and phenomena become objects of their own activities, as well as objects of their own "reflection" (if we use the traditional terms) represented, though, in the meta-system level. Hence it is apparent that the meta-system convertibility mechanism is the main source ensuring existence of reflexive processes per se, existence of reflection as a fundamental and unique phenomenon in general.

From our point of view, reflection appears to be the process responsible for connecting the general system level of organization of psychical processes (i.e. a maximum generalized level which represents all their 
totality) with the meta-system level of psyche organization. According to its mechanisms and process properties reflection in a way "duplicates" all the system of psychic processes (especially the cognitive ones) and embodies it in itself. This system is a "realizer" of reflexive phenomena and processes. At the same time, the fact that a combination of psychical processes is being transposed to the meta-system level implies that the content of the psyche system becomes their object and subject (i.e. the location they are directed to). It may be concluded that it is the metasystem level, its presence in the structure of psyche that makes possible reflexive phenomena, reflection as the unique human ability. One of the most important attributive characteristics of reflection is that it leads to "moving beyond" the system of psychic processes in a certain way; as a result, the system itself becomes eligible for its subjective representation and partial conscious supervision. It is a unique side of psyche: it contains a mechanism that permits it to overcome its own system limitations, constantly go beyond its boundaries thereby making itself a subject of its own functioning. In other words, the very organization of psyche, its very content implies and demonstrates the highest of its known levels the meta-system level. Reflection is a process means for realizing this level. The whole phenomenology of conscious, consciousness as such appears to be a productive manifestation of the aforementioned means. This constitutes the exact reason why consciousness in its process aspect is correlated with the highest meta-system level of organization of psychic processes.

Thus, the interpretation of the "meta-system level" concept suggested in this article, as well as stated assumptions that psyche belongs to systems containing an "embedded" meta-system level demonstrate that contemporary versions of the system approach are not yet fully congruent with the real complexity of psyche, its attributive nature.

Besides, these assumptions reveal real and quite specific directions of advancement of the system approach itself, as well as determine the main "vector" of its evolution. This "vector" suggests the urgency for a significant broadening of traditionally accepted conceptual points of the system approach and the necessity of supplementing it with the metasystem approach. The meta-system approach is not only a logical product of its development, its new stage with respect to the system approach, but a sort of "dialectic undertaking" as well: our investigations (Karpov, 2004b) show that the meta-system approach represents a series of quite 
general principles described within the system approach in a substantially different way. We would like to mention a single rather representative direction of such transformations.

If the system approach is primarily concerned with the search for a meta-system for the object under consideration, and then with disclosure of the principles by virtue of which it is incorporated into this meta-system and detection of extra characteristics it acquires within the meta-system, the situation is different and much more complicated concerning the systems analyzed here. On the one hand, undoubtedly, psyche, personality on the whole are objectively (ontologically) a "part of the world," i.e. appear to be a subsystem in regard to the meta-system of objective reality. In this meta-system numerous qualitative characteristics, properties etc. are gained by the psyche. On the other hand, psyche is a system with an "embedded" meta-system level. The system generates certain models serving as "duplicates" for objective reality "inside" its content, i.e. "doubles" this reality, while the meta-system itself consequently becomes included into the composition, content, and structure of psyche. Accordingly, the core of the question and the main "dimension" in studying the problem is determined not by the principles of how a system is "installed" into the meta-system, but, on the contrary, how a meta-system ontologically represented as an original one becomes "embedded" into the system, the system of the psyche? How the meta-system of objective reality, being ontologically primary to psyche, "embedded" gnoseologically and subjectively into the system of the psychical and how does it acquire a "duplicated being in it"? A certain form of inversion of "classical" relations between the system and meta-system modes takes place. It's not a system that is "embedded" into the meta-system, quite on the contrary: a meta-system is included in the system (however, we should stress that only in a certain aspect, but not ontologically). Consequently, in addition to the principles of inclusion of a system in the meta-system, the principles of inclusion of the meta-system in a system should be a subject of analysis and scientific search. "Inclusion" of the meta-system into the system (let it be merely a certain aspect, in a specific form) results in the situation when the metasystem itself starts to play the role of a certain kind of local "component" of psyche. All this leads to unusual and partially paradoxical relations between them. The meta-system remaining as it is simultaneously becomes a part, a component, a subsystem for a system that has been (and 
still is) its own "component"; the meta-system becomes a subsystem. Besides, a system incorporating a meta-system as its component begins to act as a meta-system (without losing its original system status, though). Simply speaking, a meta-system remaining as it is at the same time appears to be a system; a system remaining as it is simultaneously acts as a meta-system. The same idea can be put in another way. A certain reality may simultaneously appear to be both a meta-system and a system while these concepts (including reality they designate) are not therefore absolute, they have a relative nature: in relation to the systems with the "embedded" meta-system level they are capable of describing and characterizing one and the same reality. And vice versa, for this reality to be fully described and explained, it has to be simultaneously represented both as a system and as a meta-system, i.e. from the position of the complementation principle.

Thus, in the psychical dimension, the concepts of a system and a meta-system are not ultimate, but relative; the psychical may be found in both statuses and, moreover, combine both of them in itself. Such combination and such reversibility give rise to a real difficulty and a real foundation for unfolding of the system principles within the sphere of the psychical. This difficulty is still to be understood and explained in all its scope; although now it can and should be at least realized.

It is important to underline the following aspect in conclusion. The results of the analysis performed above confirm one of the most general gnoseological regularities (which simultaneously seems to be an argument in favour of their relevance): "an old theory (classical system approach) is in no way cancelled by a new one" (the meta-system approach), but is included in the latter as its particular, yet certainly very important component. At the same time, the "new theory," being a direct result and a natural product of the "old theory," demonstrates how exactly the limitations it contains may be overcome and creates the opportunities necessary to perform this task.

\section{References}

Anokhin, P.K. (1978). Izbrannye trudy [Selected Works]. Moscow: Nauka.

Barabanschikov, V.A., \& Nosulenko, V.N. (2004). Sistemnost'. Vospriâtie. Obŝenie [Consistency. Perception. Interaction]. Moscow: IP RAN. 
Bertalanffy, L. (1974). Istoriâ i status obŝej teorii sistem [History and Status of General System Theory]. In Sistemnye issledovaniâ, 1973 [System Research, 1973]. Moscow: Nauka.

Flavell, J.H. (1979). Metacognition and Cognitive Monitoring: A New Area of Cognitive-Developmental Inquiry. American Psychologist, 34, 906-911.

Golikov, Yu.Ya., \& Kostin, A.N. (1996). Problemy i principy issledovaniâ mežličnostnyh vzaimodejstvij v složnyh čeloveko-mašinnyh kompleksah [Problems and Principles of Research on Interpersonal Interactions in Complicated Individual-Machine Complexes]. In Sistemnye issledovaniâ, 1992-1994 [System Research, 1992-1994]. Moscow: Editorial URSS.

Haken, H. (1980). Sinergetika [Synergetics]. Moscow: Mir.

Karpov, A.V. (2003). Psihologiâ prinâtiâ resbenij [Psychology of Decision Making]. Moscow: IP RAN.

Karpov, A.V. (2004a). Metasistemnaâ organizaciâ urovnevyh struktur psihiki [Meta-System Organization of the Level Structures of the Psyche]. Moscow: IP RAN.

Karpov, A.V. (2004b). Psihologiâ refleksivnyh mehanizmov deâtel'nosti [Psychology of Reflexive Mechanisms of Activity]. Moscow: IP RAN.

Krylov, V.Yu. (1998). Psihominergetika kak vozmožnaâ novaâ paradigma psihologičeskoj nauki [Psychomynergetics as a Possibly New Paradigm of Psychological Science]. Psihologičeskij žurnal, 3, 57-63.

Leontiev, A.N. (1983). Izbrannye psihologičeskie proizvedeniâ. T. 1 [Selected Psychological Works. Vol. 1]. Moscow: Pedagogika.

Lomov, B.F. (1984). Metodologičeskie i teoretičeskie problemy psihologii [Methodological and Theoretical Problems of Psychology]. Moscow: Nauka.

Metcalfe, J., \& Shimamura, A. (1996). Metacognition: Knowing about Knowing. Cambridge: MIT Press.

Nelson, T.O., \& Narens, L. (1990). Metamemory: A Theoretical Framework and New Findings. In G. Bower (Ed.), The Psychology of Learning and Motivation. Vol. 26 (pp. 125-141). New York: Academic.

Prigogine, I., \& Stengers, I. (1986). Porâdok iz haosa: Novyj dialog čeloveka s prirodoj [Order out of Chaos: Man's New Dialogue with Nature]. Moscow: Progress.

Vekker, L.M. (1974). Psihičeskie processy. T. 1 [Psychical Processes. Vol. 1]. Leningrad: LGU.

Yzerbyt, V.Y., Lories, G., \& Dardenne, B. (Eds.). (1998). Metacognition: Cognitive and Social Dimensions. London: Sage.

Zavalishina, D.N. (1995). Polisistemnyj podhod k rešeniû myslitel'nyh zadač [PolySystem Approach to Solving Thinking Tasks]. Psihologičeskij žurnal, 6, 32-42. 